\title{
COMMENTARY
}

\section{Should hydroxyethyl starch solutions be totally banned?}

Jean-Louis Vincent ${ }^{1 *}$, John A Kellum², Andrew Shaw ${ }^{3}$ and Michael G Mythen ${ }^{4}$

\begin{abstract}
The choice of which intravenous solution to prescribe remains a matter of considerable debate in intensive care units around the world. Trends have been moving away from using hydroxyethyl starch solutions following concerns about safety. But are the available data sufficient to clearly assess the risk-benefit balance for all patients, and is there enough evidence of harm to justify removing these drugs completely from our hospitals?
\end{abstract}

The choice of which intravenous solution to prescribe is a question that arises many times a day in every intensive care unit around the world. The pendulum has been swinging away from hydroxyethyl starch (HES) solutions, in part because of the revelations of fraudulent studies conducted by Joachim Boldt [1]. Indeed, the persistence of HES molecules in the body is of serious concern and this issue can no longer be ignored by use of 'newer' starches. However, for any intravenous solution (as for any drug), a balance between risks and benefit must be considered. After all, diuretics, angiotensinconverting enzyme inhibitors, and beta-blocking agents can alter renal function in some patients but are also highly effective agents in the management of the cardiac patient.

Recent studies have provided a wealth of evidence documenting the adverse effects of HES solutions, but can they justify complete removal of these drugs from the market? Such a decision would seem to require evidence of harm in excess of benefit. Let's try to assess this balance (Figure 1) given the data provided by these recent studies.

\footnotetext{
* Correspondence: jlvincen@ulb.ac.be

'Department of Intensive Care, Erasme Hospital, Université libre de Bruxelles, route de Lennik 808, 1070, Brussels, Belgium

Full list of author information is available at the end of the article
}

\section{Was the harm signal robust?}

The effects of HES solution on renal function in the Crystalloid versus Hydroxyethyl Starch Trial (CHEST) [2] were somewhat discordant. The increase in creatinine with HES was relatively minor and urine output was initially greater, so there was actually less acute kidney injury when assessed by the R and I stages of the Risk, Injury, Failure, Loss, and End-stage renal disease criteria. There was a greater use of renal replacement therapy, but the difference concerned only 39 of 7,000 patients. The toxicity of HES solutions in the Volume Substitution and Insulin Therapy in Severe Sepsis [3] and 6S (Scandinavian Starch for Severe Sepsis/ Septic Shock trial) [4] studies was more apparent, but much larger doses (in some cases well in excess of recommendations or common practice) were used.

\section{Are the alternatives so safe?}

Even if we accept the toxicity of HES solutions, the relative safety of other solutions is not entirely clear. Gelatin solutions have not been well studied, but there do appear to be concerns for renal toxicity [5]. Similarly, there is a renal failure risk associated with excessive administration of other colloids [5]. With their high chloride load, $0.9 \%$ saline solutions may also cause harm, including an increased risk for dialysis [6,7]. Finally, hypotonic solutions, such as lactated Ringer's or Hartmann's solution, may not be desired, and the effects of some constituents, including acetate and gluconate, of other balanced solutions have not been well studied. Although both the CHEST [2] and 6S [4] trials provide evidence of comparative toxicity for saline versus HES in saline and Ringer's acetate versus HES in the same carrier, no available intravenous solution is free of potential adverse effects.

\section{Do the available studies allow us to evaluate benefit?}

If we are to judge the risk-benefit ratio for each of the available fluids, we cannot look only at studies evaluating toxicity. HES, like other colloids, is believed to provide benefit 


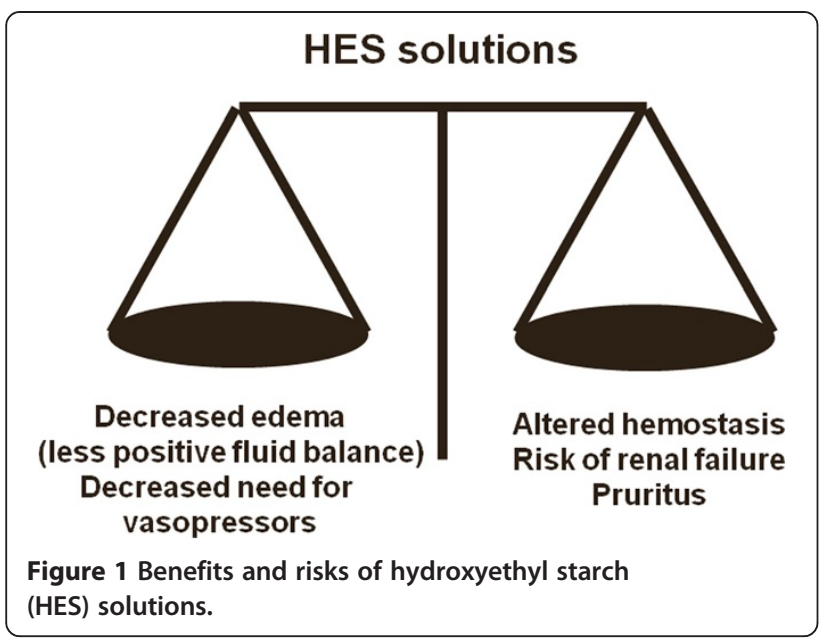

by improving the efficiency of resuscitation [8]. Efficiency, in this context, is the time to reach resuscitation goals and the volume of fluid required to achieve these goals. To some extent, this was documented in the CHEST trial [2], in which the administration of HES resulted in an initially greater urine output, a less positive fluid balance, a higher central venous pressure, and lower requirements for vasopressor agents. Furthermore, the recent Colloids Compared to Crystalloids in Fluid Resuscitation of Critically Ill Patients study, which included 3,000 patients, showed a less positive fluid balance and lower 90-day mortality rates in colloid than in crystalloid-treated patients, and the colloids administered were primarily synthetic (Djillali Annane, personal communication). In contrast, the $6 \mathrm{~S}$ study [4] could not evaluate efficiency of resuscitation, because patients had largely already achieved resuscitation goals prior to enrolment. In both studies, the central venous oxygen saturation was $74 \%$ at baseline, and the initial lactate level was only $2 \mathrm{mEq} / \mathrm{L}$ in the $6 \mathrm{~S}$ study.

Thus, the recent trials, though excellent, provide only half the information we need to be able to assess a riskbenefit relationship. These studies have clearly characterized the toxic effects of HES solutions but do not inform on potential benefit, except to demonstrate that giving fluids to already-resuscitated patients does not provide any! None of the intravenous fluids currently available may be entirely safe, especially when given in large amounts. All fluids should be considered as drugs, and no drug is risk-free. Indeed, one can consider that even oral fluids have their risks: beer, wine, and nonalcoholic beverages, such as coffee and sugar-containing beverages, should all be taken only in moderation, and even water can be harmful if taken in excess.

\section{Conclusions}

We believe that decisions about intravenous fluid therapy should be individualized on the basis of the available evidence and the clinical context. Clinicians must definitely be aware of the harmful effects attributable to HES, and use of these solutions in patients with sepsis or in bleeding patients should be undertaken only with extreme caution and only when the benefits for the individual patient are expected to exceed the risks for that individual. Eliminating these solutions completely, on the other hand, prevents their use even in situations in which they are judged by physicians to have a positive benefit-to-risk relationship. We believe that the US Food and Drug Administration has made the right decision in leaving the current HES solutions available but making specific recommendations regarding restricted use of these solutions in certain groups of patients and adding a 'black box' warning about risks of excessive bleeding [9]. This approach represents good regulatory medicine because it does not impinge on provider autonomy but ensures improved patient safety. We hope the European Medicines Agency will take a similar view.

\section{Abbreviations}

6S: Scandinavian Starch for Severe Sepsis/Septic Shock trial;

CHEST: Crystalloid versus Hydroxyethyl Starch Trial; HES: hydroxyethyl starch.

\section{Competing interests}

J-LV declares that he has no competing interests. JAK is a consultant for and has received grant support from Baxter (Deerfield, IL, USA). AS has received consulting fees from Baxter. MGM and his institution have received consulting fees from AQIX (London, UK), his institution has received grant support from Fresenius Kabi (Bad Homburg, Germany), and he has received lecture fees and travel support from Baxter, B. Braun (Melsungen, Germany), and Fresenius Kabi.

\section{Authors' contributions}

J-LV drafted the article, which was revised by JAK, AS, and MGM for critical content. All authors read and approved the final manuscript.

\section{Author details}

'Department of Intensive Care, Erasme Hospital, Université libre de Bruxelles, route de Lennik 808, 1070, Brussels, Belgium. ${ }^{2}$ School of Medicine, Department of Critical Care Medicine, Room 608, Scaife Hall, 3550 Terrace Street, Pittsburgh, PA 15261, USA. ${ }^{3}$ Department of Anesthesiology and Critical Care Medicine, Duke University Medical Center/Durham VAMC, Durham, NC 27710, USA. ${ }^{4}$ UCLH/UCL NIHR Biomedical Research Centre, Maple House, 149 Tottenham Court Road, London W1T 7DN, UK.

\section{Published: 01 Oct 2013}

\section{References}

1. Wise J: Boldt: the great pretender. BMJ 2013, 346:f1738.

2. Myburgh JA, Finfer S, Bellomo R, Billot L, Cass A, Gattas D, Glass P, Lipman J, Liu B, McArthur C, McGuinness S, Rajbhandari D, Taylor CB, Webb SA: Hydroxyethyl starch or saline for fluid resuscitation in intensive care. $N$ Engl J Med 2012, 367:1901-1911.

3. Brunkhorst FM, Engel C, Bloos F, Meier-Hellmann A, Ragaller M, Weiler N, Moerer O, Gruendling M, Oppert M, Grond S, Olthoff D, Jaschinski U, John S, Rossaint R, Welte T, Schaefer M, Kern P, Kuhnt E, Kiehntopf M, Hartog C, Natanson C, Loeffler M, Reinhart K: Intensive insulin therapy and pentastarch resuscitation in severe sepsis. N Engl J Med 2008, 358:125-139.

4. Perner A, Haase N, Guttormsen AB, Tenhunen J, Klemenzson G, Aneman A Madsen KR, Moller MH, Elkjaer JM, Poulsen LM, Bendtsen A, Winding R, Steensen M, Berezowicz P, Soe-Jensen P, Bestle M, Strand K, Wiis J, White JO, Thornberg KJ, Quist L, Nielsen J, Andersen LH, Holst LB, Thormar K, 
Kjaeldgaard AL, Fabritius ML, Mondrup F, Pott FC, Moller TP, Winkel P, Wetterslev J: Hydroxyethyl starch 130/0.42 versus Ringer's acetate in severe sepsis. N Engl J Med 2012, 367:124-134.

5. Davidson IJ: Renal impact of fluid management with colloids: a comparative review. Eur J Anaesthesiol 2006, 23:721-738.

6. Shaw AD, Bagshaw SM, Goldstein SL, Scherer LA, Duan M, Schermer CR Kellum JA: Major complications, mortality, and resource utilization after open abdominal surgery: $0.9 \%$ saline compared to Plasma-Lyte. Ann Surg 2012, 255:821-829.

7. Yunos NM, Bellomo R, Hegarty C, Story D, Ho L, Bailey M: Association between a chloride-liberal vs chloride-restrictive intravenous fluid administration strategy and kidney injury in critically ill adults. JAMA 2012, 308:1566-1572.

8. Kellum JA, James MF: Why do intensivists still use hydroxyethyl starch? Crit Care Med 2010, 38:2260-2262.

9. US Food and Drug Administration: FDA Safety Communication: boxed Warning on increased mortality and severe renal injury, and additional warning on risk of bleeding, for use of hydroxyethyl starch solutions in some settings. http://www.fda.gov/biologicsbloodvaccines/safetyavailability/ ucm358271.htm\#professionals.

$10.1186 / \mathrm{cc} 13027$

Cite this article as: Vincent et al: Should hydroxyethyl starch solutions be totally banned? Critical Care 2013, 17:193 